\title{
Dez anos de ocupações organizadas em Belo Horizonte: radicalizando a luta pela moradia e articulando ativismos contra o urbanismo neoliberal
}

\author{
Ten years of organized housing squats in Belo Horizonte: \\ radicalizing the struggle for housing and articulating \\ activisms against neoliberal urbanism
}

Marina Sanders Paolinelli [l] Thiago Canettieri [II]

\section{Resumo}

Este artigo é uma tentativa de balanço dos dez anos de um ciclo importante de lutas organizadas por movimentos sociais em Belo Horizonte. Ao longo desse tempo, os movimentos transformaram-se, ampliaram suas pautas para além do direito à moradia e assumiram estratégias de luta ampliada pelo direito à cidade - e contra o processo recente de neoliberalização da gestão municipal - que tomaram principalmente a forma de ocupações organizadas. Durante o período, caracterizado por uma hibridização das lutas urbanas, foi alterado significativamente o padrão de relacionamento dos movimentos com as instituições, que passou a se basear na ação direta, na ação institucional e na ação cotidiana.

Palavras-chave: ocupações organizadas; direito à cidade; movimentos sociais; lutas sociais urbanas.

\begin{abstract}
This paper is an attempt to evaluate ten years of an important cycle of struggles organized by social movements in the city of Belo Horizonte. Over this period, the movements underwent transformations, expanded their agenda beyond the right to housing, and adopted strategies of an expanded struggle for the right to the city, opposing the recent neoliberalization process of the municipal management. These strategies have mainly taken the form of organized squatting. During the period, characterized by a hybridization of urban struggles, the pattern of relationship between the movements and the institutions was significantly changed and started to be based on direct action, institutional action, and everyday action.
\end{abstract}

Keywords: organized squats; right to the city; social movements; urban grassroots struggles. 


\section{Introdução}

Este artigo é uma tentativa de balanço dos dez anos de um importante ciclo de lutas mobilizadas por movimentos sociais em Belo Horizonte, que se expressaram principalmente na forma de ocupações organizadas. Buscamos, a partir da narrativa desse período - que se inicia na ocupação Dandara (2009) e finda na negociação de despejo da ocupação Vicentão (2019) -, sugerir uma interpretação. Essa investigação apenas foi possível devido ao grande volume de trabalhos sobre o assunto desenvolvido nas universidades e nos programas de pós-graduação, que deu estofo e material para a pesquisa. Mas, mais que um momento de intensa produtividade acadêmica, a série de debates decorrentes desse ciclo significou um período emblemático de reflexão sobre o urbano e os movimentos sociais em Belo Horizonte, que merece o esforço de sistematização deste artigo.

Buscamos mostrar, aqui, como os movimentos de luta por moradia atuantes em Belo Horizonte têm se radicalizado e se tornado uma forma de ativismo ampliado pelo direito à cidade. Influenciados pelas jornadas de juIho de 2013 e pelas mobilizações contra os megaeventos, os grupos organizados ligados às ocupações urbanas complexificaram seu repertório de organização e ação política e desenvolveram uma crítica aprofundada ao planejamento urbano contemporâneo. Desde então, têm criado outras formas de relação com o Estado, usando uma nova interlocução com sociedade civil, academia, redes de advogados populares, Defensoria e Ministério Público, às margens das esferas participativas construídas nos anos 1990.
Para endossar esse argumento, levantamos um histórico detalhado sobre a atuação desses movimentos durante as últimas décadas, desde as primeiras ocupações organizadas de terrenos periféricos até as recentes ocupações de edificações na área central, focando no entrecruzamento dos três principais tipos de atuação: a ação direta, a ação institucional e a ação cotidiana. Sustentando a argumentação, propomos inicialmente uma breve explanação sobre o que significam as ocupações organizadas no contexto do capitalismo periférico e sobre o início de sua expressão no Brasil.

\section{Ocupações organizadas no contexto do capitalismo periférico}

Antes de entrar no histórico das ocupações organizadas de Belo Horizonte, é preciso compreender o que significa essa forma de luta urbana no contexto da urbanização no capitalismo periférico. Conforme argumentado por Oliveira (2003), a forma de inserção do Brasil na economia mundial capitalista, de maneira tardia e dependente, resultou numa forma de industrialização sui generis: uma industrialização dos baixos salários. Assim, por determinação da economia política dependente, a modernidade capitalista do Brasil teve que se haver, numa imbricada dialética, com o pré-moderno. Práticas vistas como atrasadas, como a autoconstrução e o mercado informal de moradias, foram condições da industrialização brasileira, seja no período pós-1930 ou pós-1970. 0 resultado disso, segundo Maricato (2003), foi uma urbanização dos baixos salários. 
Em muitos países de economia periférica, como o Brasil, a ausência de um Estado de bem-estar na gestão da reprodução da vida urbana impulsionou não somente a informalidade habitacional, mas também a organização popular em busca de direitos: pelo reconhecimento dos territórios, a conquista de infraestrutura urbana, serviços públicos, etc. Dessa forma, os territórios populares periféricos consolidaram-se, ao mesmo tempo, como locais da superexploração da mão de obra que sustentam a acumulação dependente - como argumentado por Oliveira (2003) e Maricato (2003) - e como lugares da formação da cidadania insurgente ${ }^{1}$ e dos territórios em resistên$\mathrm{cia}^{2}{ }^{2}$ como argumentado por Holston (2013) e Zibechi (2015).

De forma bastante simplificada, a urbanização dos baixos salários possui duas principais formas de expressão. A primeira, mais recorrente e antiga historicamente, é a prática informal autônoma, espontânea e gradual dos pobres urbanos - vilas, favelas, periferias. A segunda seria a expressão da ação consciente de uma luta organizada, com participação de movimentos sociais - as ocupações organizadas. Conforme Zibechi (2015, p. 42), uma ocupação organizada pode ser caracterizada pela:

[...] organização coletiva anterior à ocupação, com a eleição cuidadosa de um espaço adequado e de uma ação surpresa, preferencialmente durante a noite, na busca de um guarda-chuva legal com base nas relações com as igrejas ou partidos políticos e na elaboração de um discurso legitimador da ação clandestina.

Segundo Zibechi (ibid.), a primeira ocupação maciça organizada na América Latina foi La Victoria, realizada em 1957 em Santiago.
No Brasil, nesse período, eram os movimentos dos favelados e das associações de bairro das periferias que emergiam nas cidades. Esses movimentos, precursores da luta pela reforma urbana, transformaram-se durante o governo militar até ganharem força novamente durante os anos 1980, demonstrando um papel fundamental de mobilização popular durante a constituinte (Holston, 2013).

No período, todo o País estava contaminado pelos anseios de democratização que fez aparecer (e reaparecer) no cenário político toda sorte de movimento social, exigindo melhores condições de vida e de incidência política. Por meio da consolidação da ideia de "direito a direitos" (ibid.), as classes populares brasileiras canalizaram-se para o plano-legal constitucional. Para além da reforma urbana, o "direito à moradia" passou a ganhar uma grande centralidade. Sendo assim, a partir dos anos 1980 surgiu uma série de movimentos de luta por moradia ${ }^{3}$ para exigir do Estado providências quanto à provisão de habitação. Nesse contexto, as ocupações organizadas tornaram-se uma forte ferramenta de mobilização e negociação, espalhando-se e ganhando força no Brasil. 0 grande marco histórico desse período foi a ocupação simultânea de dezenas de terrenos, envolvendo cerca de 50 mil famílias, pela União dos Movimentos de Moradia de São Paulo, em 1987. Para além de uma ferramenta de pressão, as ocupações passaram a representar, de fato, uma alternativa de moradia, na medida em que a produção habitacional estatal continuou insuficiente diante das demandas urbanas. Como afirma Canettieri (2014, p. 26):

As ocupações são, portanto, essenciais para grande parcela da população que vive à margem do acesso formal à moradia. 
Em primeiro lugar, pela própria necessidade básica do ser humano de moradia. Mas as ocupações oferecem outros ganhos, como a recomposição do salário desses trabalhadores, muitas vezes já muito baixo. Com a ocupação o indivíduo se isenta de uma série de custos, como custo de luz, água, impostos e aluguéis, o que acaba proporcionando a oportunidade de aproveitar o dinheiro do salário escasso em outras áreas, como a alimentação.

A inclusão da "função social da propriedade" na Constituição de 1988 tornou ilegal a especulação imobiliária e ofereceu, aos movimentos sociais, um reforço na legitimação da ocupação de terrenos e imóveis. A partir de então, ocupar um terreno passou a ser "fazer valer um direito, enquanto deixá-lo vago significa um desrespeito à lei" (Lourenço, 2014, p. 96), e ocupações organizadas passaram a pipocar por todo o País. Como veremos a seguir, no caso de Belo Horizonte, a emergência dessas formas vai se dar em um momento ainda posterior, durante outro contexto político.

\section{Gestão participativa e sufocamento das ocupações}

Em Belo Horizonte, assim como no contexto nacional, o fim da década de 1980 foi marcado por uma série de mobilizações sociais ligadas aos territórios populares, que também tiveram participação na luta pela reforma urbana. Destacavam-se, no período, os movimentos dos favelados, que influenciaram diretamente a criação de uma política municipal precursora de urbanização e regularização de favelas o Programa Municipal de Regularização de
Favelas (Profavela). Pela primeira vez na história do Brasil, o poder público reconhecia esses territórios e previa acesso a políticas públicas (Freitas, 2015), o que influenciou posteriormente a legislação nacional. ${ }^{4}$

Ocorreu também, no município, a formação de diversos movimentos novos, que, articulados com a pauta nacional do direito à moradia, reivindicavam a provisão habitacional como dever do Estado. Várias experiências contaminavam a população favelada e davam força a essa pauta, como, por exemplo, os loteamentos associativos, sob a liderança do padre Piggi; a conquista do conjunto do bairro Taquari pelas associações de moradores da favela; as ocupações do pátio da Igreja São José, entre outros (Bittencourt, 2016).

Como um acúmulo das lutas urbanas travadas em Belo Horizonte, foi construída a Frente BH Popular, canalizada na candidatura de Patrus Ananias (PT) à prefeitura, que alcançou um expressivo resultado nas eleições. Durante seu governo (1993-1996), foram criadas as primeiras políticas urbanas e habitacionais municipais de amplitude. Conforme é analisado por Mônica Bedê (2005), foi, nessa gestão, que se estruturaram princípios, prioridades, critérios, linhas de atuação e instrumentos a serem adotados, deixando para trás o caráter residual - e, muitas vezes, clientelista - da política urbana do passado. Deve ser salientado, conforme Bedê (ibid.), que esse processo também teve como uma de suas bases a integração com um quadro técnico ligado ao Partido dos Trabalhadores - que encampou a pauta da reforma urbana dentro da gestão.

Foi, então, inaugurada uma nova política habitacional, com a criação da Companhia Urbanizadora de Belo Horizonte (Urbel) (órgão 
executor da política, lei n. 6.508/1994), do Fundo Municipal de Habitação (FMH) (lei n. 6.325/1993) e do Conselho Municipal de Habitação (CMH) (órgão deliberativo com cadeiras reservadas para o movimento popular, lei n. 6.325/1993). A política mobilizou arranjos e fundos necessários para a viabilização de diversos programas, entre eles, 0 Orçamento Participativo da Habitação.

Devido à expectativa de conquista de espaço político e de moradias produzidas pelos programas municipais, nesse período houve uma redução significativa de ocupações organizadas na cidade. Bedê afirma que havia também entre os quadros da prefeitura a intenção de constranger e estancar os processos de ocupações que haviam ocorrido no período anterior à eleição. Nas palavras da autora:

[...] isso talvez justifique o rigor do governo na adoção de critérios e procedimentos para atendimento dessas famílias, visando, por um lado, restringir possíveis práticas ilícitas, mas também, por outro lado, desestimular as ocupações. (Ibid., p. 222)

No entanto, conforme avaliado por Bittencourt (2016), a produção habitacional da Frente BH Popular foi muito restrita diante das demandas do período, e não foi possível lograr uma conscientização ampla sobre o envolvimento nas esferas participativas, que ficou limitada a algumas lideranças populares, militantes e técnicos da prefeitura. 0 resultado dessa conjuntura foi a criação de um falso antagonismo entre os movimentos: aqueles que se organizavam em torno dos núcleos ligados à prefeitura e aguardavam uma produção de moradias (insuficiente); e aqueles que, mesmo isolados (politicamente e institucionalmente), insistiam nas ocupações. Os últimos, sem apoio da maior parte dos movimentos e sem respaldo da gestão municipal, minguaram.

Com a desmobilização dos movimentos que atuavam na prática das ocupações e a absorção dos outros dentro da hegemonia do pensamento único no interior do Estado, havia, mesmo que com as melhores das intenções, desferido-se um duro golpe contra os movimentos de moradia locais, que limitaram suas ações ao aparato burocrático estatal e tiveram sua influência política restrita à participação (não paritária) nos conselhos (ibid.). 0 horizonte de expectativas dos movimentos de moradia encurtou-se ainda mais quando as gestões seguintes, de Célio de Castro (1997-2001), Fernando Pimentel (2001-2008) e Márcio Lacerda (2009-2016), não deram continuidade aos processos instaurados e, pelo contrário, dilapidaram as esferas de participação, e os programas mais progressistas foram inutilizados.

\section{Gestão empresarial e reativação das ocupações organizadas}

Depois do fim dos anos 1990, ocorreu um giro na gestão municipal. Se, no projeto da Frente BH Popular, estava descrito o compromisso com a construção participativa da cidade e das políticas públicas, nas gestões que sucederam a de Patrus Ananias, em especial de Pimentel (PT) e Lacerda (PSB), o compromisso com os setores populares foi colocado para escanteio. A gestão urbana foi atualizada para atender às tendências do ideário neoliberal, ${ }^{5}$ do planejamento estratégico ${ }^{6}$ e do empresariamento 
urbano. ${ }^{7} 0$ resultado foi uma modificação substancial das políticas participativas municipais e da condução da gestão urbana de forma geral.

No plano de governo de Pimentel, encontravam-se expressões como a "expansão da cidade no cenário internacional", "sediar grandes eventos", "revitalização através de parcerias com o setor privado de espaços da cidade" (Franco, 2007 apud Bittencourt, 2016). Alinhada com seu discurso, sua prática de gestão significou uma verdadeira "desinversão" de prioridades: em detrimento da participação e do atendimento às necessidades dos munícipes, estavam colocados o atendimento às demandas da acumulação e a inserção da cidade na disputa pelos mais variados investimentos externos (Bittencourt, 2016).

Um exemplo dessa prática foi a implantação, a partir de 2005, do Vila Viva, programa de intervenção em vilas e favelas para a erradicação de áreas de risco. De origem nos anos 1990 e aparentemente bem-intencionado, 0 programa começou a receber diversas críticas, vindas tanto do meio acadêmico quanto dos movimentos sociais e de populações atingidas - que apelidaram o programa de Vila Morta. ${ }^{8}$ As intervenções têm resultado em um grande volume de remoções de famílias, que, ou recebem indenizações insuficientes para se manterem na comunidade, ${ }^{9}$ ou são reassentadas em "predinhos", nem sempre compatíveis com suas lógicas de moradia (Melo, 2011). Segundo Bittencourt (2016, p. 38), as obras do programa não foram "realizadas diretamente pelo poder público e/ou formas associativas e/ou cooperativas dos seus próprios moradores, mas por agentes tradicionais do circuito capitalista de produção do espaço: grandes construtoras e empreiteiras".

Nesse cenário de insatisfação, as mobilizações populares desvinculadas do poder municipal começaram a se fortalecer novamente, com a reativação de coletivos militantes e movimentos sociais. Esse momento representou um novo ciclo de luta urbana em Belo Horizonte, caracterizado pela politização de esquerda nas lutas por moradia; por um discurso ampliado sobre o direito à cidade, para além da moradia; e por um novo repertório de ação política - sustentado principalmente na realização de ocupações organizadas, que ressurgem enquanto uma potente ferramenta de luta.

Da aproximação de uma juventude universitária de esquerda com antigas lideranças do movimento de moradia formaram-se as Brigadas Populares, ${ }^{10}$ que entraram na linha de frente na tarefa de construir ocupações organizadas na cidade. As primeiras tentativas se deram em edificações próximas à região central e foram todas frustradas. Devido à intensa repressão pelo poder público, as ocupações Caracol (2006 - Bairro Serra), João de Barro I (2007 - Bairro Serra), João de Barro II (2007 Bairro Pampulha) e João de Barro III (2008 Bairro Barro Preto), foram despejadas em menos de seis meses.

Segundo Bittencourt (ibid.), depois dessa breve onda de ocupações verticais reprimidas, houve uma inflexão na trajetória desses movimentos. Foi abandonada a ideia de ocupar edificações verticalizadas em áreas centrais para se assumir a estratégia da ocupação de terrenos nas áreas periféricas da cidade, apostando-se na autoconstrução e no trabalho coletivo como formas de criar novos territórios 
populares. Essa tática se demonstrou muito mais bem-sucedida quanto à garantia da permanência e assegurou a consolidação desse novo ciclo de lutas em Belo Horizonte.

A primeira ocupação a lograr sua permanência foi Camilo Torres (2008 - Barreiro). Mesmo com um pequeno número de famílias, essa experiência ofereceu um rico aprendizado para as 25 experiências subsequentes, que hoje abrigam mais de 15 mil famílias em Belo Horizonte e em sua Região Metropolitana. ${ }^{11}$ Todavia, esses dez anos de trajetória não se passaram sem embates. Foi preciso muita organização e amadurecimento político para resistir aos desafios travados com a gestão municipal.

Após o mandato de Pimentel, Márcio Lacerda (PSB) foi apresentado como seu sucessor e foi eleito em 2009. Lacerda encaminhou até às últimas consequências uma postura autoritária, pouco aberta aos movimentos sociais e de radicalização do ideário neoliberal e empresarial da gestão anterior. Sua lista de ações problemáticas como prefeito foi extensa: lançou o decreto municipal que proibiu a realização de eventos de qualquer natureza na praça da Estação, ponto emblemático de manifestação popular da cidade; criou uma campanha publicitária sobre a forma "correta" de utilização do espaço urbano, que impediu o trabalho de profissionais autônomos, como pipoqueiros, na área central; suprimiu, no contexto da Copa do Mundo, milhares de árvores no Mineirão para dar lugar a estacionamentos e ao alargamento de vias; planejou uma via e um complexo de viadutos na MG-710, desalojando centenas de favelados; lançou os primeiros editais para a privatização dos parques municipais; tentou implementar uma gigantesca operação urbana real state market friendly, criou a empresa PBH Ativos S/A, destinada ao desenvolvimento de parcerias público-privadas e à realização da securitização da dívida ativa do município, ${ }^{12}$ entre muitas outras. Foi, portanto, sob o regime de Lacerda que se consolidou a empresificação da política no município (Canettieri, 2017). Sua gestão empresarial ${ }^{13} \mathrm{im}$ plicou uma limitação democrática que esvaziou os espaços de participação.

\section{Ocupações organizadas, ativismos e mobilizações contra a gestão neoliberal}

Ao longo desse amplo movimento de privatização da cidade, cerceamento de direitos e adoção do corolário neoliberal, Belo Horizonte viu florescer uma ampla gama de movimentos sociais. Contra o cerceamento das liberdades dos ambulantes, artistas, transeuntes e manifestantes políticos na praça da Estação, foi criada a Praia da Estação, ${ }^{14}$ evento regular que ocupa a praça desde 2010. Em 2011, contra os mandos e desmandos da gestão, foi criado 0 movimento Fora Lacerda!, ${ }^{15}$ que articulou uma ampla rede de organizações e ganhou espaço nas redes sociais.

Contra os despejos e a redução dos processos participativos e na luta pelo direito à moradia e à cidade, além das Brigadas Populares, ganhou destaque, no período, o Movimento de Luta nos Bairros, Vilas e Favelas (MLB). Fundado, no final dos anos 1990, o grupo consolidou uma das mais importantes participações na organização de ocupações da última década. Fortaleceram-se também, apoiando a formação e a consolidação de 
ocupações, as Lutas Populares, a Frente Terra e Autonomia e a Comissão Pastoral da Terra - com a liderança de frei Gilvander, figura emblemática da luta pela reforma agrária e urbana em Minas Gerais.

A primeira grande ocupação organizada a despontar no início da gestão Lacerda foi Dandara, em 2009, ${ }^{16}$ que logo se tornou um paradigma. Abrigando 1.500 famílias e construindo um amplo apoio da sociedade civil, de intelectuais, acadêmicos, artistas e de movimentos sociais diversos, a ocupação logrou as condições para um novo enfrentamento em relação à prefeitura e se fortaleceu como uma verdadeira possibilidade de luta e de consolidação da moradia. Vale lembrar que a ocupação Dandara foi emblemática, não apenas pela sua dimensão ou por sua capacidade de resistir às ameaças de despejo, mas também pelo momento político em que se inseriu, já que 2009 foi o ano de criação do programa federal Minha Casa Minha Vida (PMCMV). Ainda que tenha sido propagandeado como um programa de provisão habitacional, o PMCMV buscava, na realidade, trazer uma alternativa econômica ante a crise internacional de 2008, estimulando a criação de empregos e de investimentos no setor da construção civil. Como destacado por Arantes e Fix (2009, s.p.):

97\% do subsídio público disponibilizado pelo pacote habitacional, com recursos da União e do FGTS, são destinados à oferta e produção direta por construtoras privadas, e apenas $3 \%$ a entidades sem fins lucrativos, cooperativas e movimento sociais, para produção de habitação por autogestão. 0 pacote não contempla a promoção estatal (projetos e licitações comandados por órgãos públicos) [...].
Devido aos vastos recursos federais mobilizados para deslanchar o programa, o modelo de provisão habitacional do PMCMV tornou-se, logo após seu lançamento, a forma hegemônica de produção de unidades no Brasil. Com isso, muitos movimentos urbanos trataram de "demandar mais Minha Casa Minha Vida" ou de disputar os escassos recursos destinados às entidades (Guerreiro, 2017). No caso de Belo Horizonte, ${ }^{17}$ que havia desenvolvido suas próprias regras de seleção de famílias nos programas municipais anteriores, o resultado foi, segundo Paolinelli (2018, p.18):

Com a introdução dos critérios do programa Minha Casa Minha Vida no município, a política local se enfraqueceu ainda mais, e os núcleos organizados, que haviam lutado durante anos junto à prefeitura, ficaram no limbo da política municipal na espera por unidades, formando o "passivo do OPH". Em meio a esses problemas, os movimentos de luta pela moradia local acabaram se dividindo: enquanto militantes antigos dominaram o Conselho Municipal de Habitação, limitando a renovação das pautas para reforçar a cobrança das promessas do passado, novas lideranças emergiram, se arriscando na construção de moradias a partir de ocupações organizadas.

Sendo assim, depois de Dandara, em apenas dois anos, outras seis ocupações surgiram em Belo Horizonte (Bittencourt, 2016). Todas elas organizadas com apoio técnico e de movimentos sociais e com uma ampla rede capaz de se mobilizar em casos de maiores acirramentos com o poder público. ${ }^{18}$ Assim, mesmo nas situações extremas, em que o apara=to repressor da polícia era fortemente mobilizado (de tropa de choque a helicópteros, 
de cachorros a blindados), o movimento social, por várias vias, conseguiu fazer frente. A politização e a vinculação com advogados populares e técnicos davam legitimidade. Uma estratégia importante era a ativação de uma rede de contatos capaz de contribuir na resistência e reverter o despejo: representantes do legislativo e de suas comissões, defensores públicos, repórteres, artistas, intelectuais ou qualquer um que pudesse pressionar as autoridades e contribuir estando presente nos momentos de resistência. Assim, entre 2009 e 2015 nenhuma ocupação organizada por movimentos chegou a ser despejada em Belo Horizonte. ${ }^{19}$

Não se pode esquecer também a importância das Jornadas de Junho de 2013, que deram força e legitimidade para os movimentos sociais envolvidos nas ações diretas de ocupação. Na explosão das ruas, toda uma miríade de atores - organizados na Assembleia Popular Horizontal $(\mathrm{APH})^{20}$ - encontrou condições de vocalizar suas demandas e insatisfações, criando uma vasta articulação de movimentos, coletivos, partidos e autônomos, e fortaleceu a resistência das ocupações por meio da construção de amplas redes de solidariedade. Essas redes tiveram participação na linha de frente das manifestações em Belo Horizonte no período. 0 Comitê dos Atingidos pela Copa (Copac) ${ }^{21}$ também teve uma participação fundamental na canalização e organização de uma série de grupos e populações prejudicadas durante as Copas (Copa das Confederações, em 2013, e Copa do Mundo, em 2014).

Ainda em 2013, os movimentos passaram a contribuir de maneira orgânica na ocupação Izidora, ${ }^{22}$ dando a ela todas as características de uma ocupação organizada. Com a legitimidade em alta e uma grande rede de apoiadores, os movimentos viram-se numa correlação de forças favorável, podendo radicalizar, ainda mais, suas ações e demandas. Por exemplo, quando a ocupação Izidora ainda era um "pequeno território", com 230 famílias, foi realizada uma ocupação do prédio da Prefeitura para exigir um espaço de negociação para sua permanência. Conquistada a abertura, a ocupação explodiu e aumentou dez vezes de tamanho nos meses seguintes.

Junto dessa movimentação, veio uma ampliação das pautas sociais, como a incorporação de movimentos ligados ao transporte - como o Tarifa Zero ${ }^{23}$-, à cultura - com a criação do Espaço Comum Luiz Estrela ${ }^{24}$-, ao movimento negro, feminista e a uma série de outros coletivos da cidade. Foi também em 2013 a ocupação da Câmara Municipal pela redução da passagem de ônibus, a abertura da "caixa preta das empresas de ônibus" e uma CPI da BHTrans, que agregou vários movimentos e ativistas durante uma semana de discussões e de convivência. Conforme Neves et al. (2018, p. 237), "o avanço das lutas territoriais em Belo Horizonte se realiza principalmente em função dos processos de hibridações que envolvem seus modelos operacionais mais gerais e tecnopolíticos, suas táticas, estratégias e objetivos".

No entanto, o mesmo aparato policial mobilizado pelo estado de Minas Gerais nas Copas - responsável por reprimir as manifestações de julho de 2013 - também passou a ser direcionado para o uso "cotidiano" do controle urbano. Várias foram as marchas e as mobilizações reprimidas pela polícia no período, e a prática dos chamados despejos administrativos contra as ocupações espontâneas se tornaram recorrentes, resultando em violência 
e desrespeito aos direitos básicos. Famílias despejadas, embora sem a construção de um movimento, recebiam solidariedade e, muitas vezes, passavam a se organizar para novas ocupações. Apenas no ano de 2014 foram quatro novas ocupações organizadas em Belo Horizonte e em municípios vizinhos.

Em julho de 2014, um grupo considerável de militantes, moradores de ocupações organizadas e apoiadores, ocupou, simultaneamente, o prédio da Advocacia Geral do Estado, a Urbel e a Prefeitura de Belo Horizonte, com uma pauta clara: o fim da prática de despejos violentos, sem negociação ou alternativas, que ocorriam na gestão de Lacerda. A polícia reagiu de forma extremamente violenta, negando-se a negociar com os manifestantes e usando de uma força desproporcional para dispersar o movimento. ${ }^{25}$ Mesmo sem alcançar o atendimento da pauta colocada nessa ação, o movimento reacendeu, incutindo ânimo na ampla rede de movimentos e apoiadores para a retomada das ruas no contexto da militarização da Copa do Mundo.

A persistência do engajamento político continuou sendo a grande tônica em Belo Horizonte, mesmo depois do fim das Copas. Ao longo de 2014, floresceu uma série de movimentos - contra a Operação Urbana Consorciada Nova $\mathrm{BH}_{1}{ }^{26}$ o corte de árvores (Fica Ficus), ${ }^{27}$ a entrega de áreas verdes para o capital imobiliário (Movimento Parque Jar$\operatorname{dim}$ América), ${ }^{28}$ o aumento do preço das passagens dos coletivos - como investigado por Veloso (2015) - entre outros. Acompanhando e dando suporte a esses movimentos, cabe destacar aqui o papel do grupo de pesquisa Indisciplinar. ${ }^{29}$ Toda essa efervescência levou a uma ampla participação do setor popular organizado na IV Conferência Municipal de Política Urbana (IV CMPU), realizada entre 2013 e 2014, com a pauta da revisão do Plano Diretor do município. Com o apoio de técnicos da prefeitura alinhados com a pauta da reforma urbana, várias demandas foram discutidas no evento e contempladas no projeto de lei resultante, mesmo com a tentativa de boicote liderada pelo setor empresarial. ${ }^{30} \mathrm{En}$ tre os avanços, foi estabelecido o Coeficiente Básico de Construção 1 em todo o município e regulamentada a Outorga Onerosa do Direito de Construir (OODC); e foram criados Fundos de subsídio ao transporte público e à habitação popular. Entretanto, apenas as ocupações organizadas com mais de cinco anos de existência foram reconhecidas como Áreas de Especial Interesse Social (Aeis) e Zonas de Especial Interesse Social (Zeis). Para reverter a decisão, movimentos buscaram respaldo na Câmara. 0 gabinete do vereador Gilson Reis ( $P C$ doB) acolheu a demanda e formulou uma emenda parlamentar para incorporar as demais ocupações no projeto de lei.

No entanto, até o momento presente, a revisão do Plano Diretor de Belo Horizonte resultante da IV CMPU não foi aprovada. ${ }^{31}$ Desde que o projeto de lei saiu do Executivo e foi direcionado para votação no Legislativo, em 2015, tem sofrido uma intensa rejeição do setor empresarial, que tem tentado influenciar os vereadores e a sociedade civil contra o projeto através de uma campanha publicitária falaciosa, nomeada Mais Imposto Não BH. ${ }^{32}$ Desde então, fazendo frente, vários movimentos sociais têm se articulado, colocando pressão para a aprovação do plano através da campanha Vereador, aprove o Plano Diretor! ${ }^{33}$ 


\section{Descoberta do continente cotidiano e suas formas de atuação política}

Em 2015, depois do refluxo das manifestações contra as Copas, a prefeitura aumentou os esforços para remover as ocupações da Izidora. ${ }^{34}$ Sua proposta era iniciar ali uma Operação Urbana Simplificada e permitir a construção de conjuntos do PMCMV. A colisão entre as ocupações organizadas e o programa estatal hegemônico de provisão habitacional se tornou evidente. A ordem de despejo foi emitida e foi revertida várias vezes pelos advogados populares, pela ampla mobilização da rede Resiste Izidora e pela ação direta dos movimentos (Franzoni, 2018; Bizzoto, 2015).

Conseguiram essa vitória, entre outras coisas, com enormes marchas realizadas por famílias, militantes e apoiadores, que saíam das ocupações e se deslocavam, a pé, na principal via de acesso ao Aeroporto Internacional de Confins e à Cidade Administrativa do Estado percurso de mais de 30 quilômetros. Diversas vezes, as marchas foram reprimidas pela polícia militar com bombas de efeito moral e cargas de cavalaria. ${ }^{35}$ Mesmo diante dessa truculência, as mobilizações continuaram, e a articulação em torno da defesa da Izidora não parou de crescer e de se fortalecer. Naquele momento, o recém-eleito governador, Fernando Pimentel (PT), viu-se constrangido a oferecer, ao menos por parte do Estado, um espaço de negociação. Logrou-se, assim, a conquista da Mesa de Diálogo sobre conflitos fundiários do Governo do Estado, importante, não apenas para a Izidora, mas para várias ocupações e conflitos fundiários posteriores.
Apesar da conquista da mesa de negociação, um dos maiores méritos do processo de resistência da Izidora foi, na verdade, evidenciar que o estar junto cotidianamente tinha uma potência capaz de criar confiança entre os sujeitos e, com isso, fortalecer todo o movimento. Primeiro, de maneira informal e inconsciente, diante dos momentos de tensão e ansiedade por conta do despejo iminente, as pessoas utilizavam cada vez mais os espaços comunitários - durante os meses de inverno, grandes fogueiras mantiveram-se acesas em frente ao barracão que acolhia os ansiosos. Depois disso, os movimentos passaram a gestar e desenvolver experiências de vida cotidiana entre moradores e grupos parceiros. Este não é um capítulo menor na história da resistência em Belo Horizonte, pois significou uma inflexão na prática dos movimentos sociais.

As Brigadas Populares passaram a se articular para além dos espaços de formação e incidência política para pensar espaços comunitários cotidianos. Surgiram diversas formas de desenvolver valores de uso coletivo (Valle, 2015), como as hortas comunitárias e a agroecologia, que articularam a aproximação da pauta dos movimentos sociais, a população periférica e coletivos de produtores agroecológicos sob um único movimento: Agroecologia na Periferia (Tofanelli, 2018). Outra expressão desse trabalho cotidiano, dessa vez direcionada à pauta da educação, foi a fundação, no ano de 2016, do Cursinho Popular Milton Santos projeto de educação crítica e de promoção do acesso à universidade pública pelos moradores da e na ocupação Novo Paraíso, com 0 apoio das Brigadas Populares. No mesmo ano, diante de sucessivas repressões ao trabalho já precarizado - dos vendedores ambulantes e 
camelôs, os movimentos sociais de Belo Horizonte lançaram também a campanha que ficou conhecida como Dignidade Ambulante. Os comerciantes informais, muita das vezes homens jovens desempregados que moravam nas periferias metropolitanas, sofriam com as apreensões de mercadorias e a arbitrariedade da ação violenta da guarda municipal.

Ainda na Izidora, em março de 2017, os moradores decidiram refazer o Barracão Comunitário em uma construção de alvenaria (Franzoni, 2018), e o rebatizaram como Zoca - sigla para Zona Ocupada de Cultura e Arte, mas também em homenagem a Maria da Conceição, a Zoca, precursora da luta pela moradia na região. 0 Centro de Poder Popular Zoca, ainda em construção, compreende banheiros, cozinha coletiva e salas que abrigam projetos artísticos, oficinas, celebrações religiosas e reuniões. Também se logrou o avanço de uma importante pauta feminista dentro dos movimentos sociais: a discussão sobre a sujeição das mulheres a jornadas duplas de trabalho devido à falta de cuidado compartilhado dos filhos, que também geravam dificuldades na condução das atividades da militância pelas lideranças femininas. Uma forma de atacar o problema de maneira coletiva e compartilhada, tratando-o como uma questão política, foi a criação da Creche Tia Carminha, na ocupação Eliana Silva.

Com isso, parecia estar acontecendo com os movimentos locais uma ampliação de suas pautas, incorporando os vários âmbitos da vida: o trabalho, a reprodução cotidiana, a cultura, o acesso a alimentos de qualidade, a segurança de posse, a educação, entre outros. ${ }^{36}$ Essa ampliação foi e ainda é essencial para solidificar a cultura militante e manter, na ordem do cotidiano, as ações de politização e resistência.

\section{Recrudescimento da gestão empresarial, abertura de novas brechas políticas e a conquista do centro}

Depois de 2016, uma nova conjuntura política estabeleceu-se em Belo Horizonte, afetando diretamente a organização de ocupações. 0 cenário nacional, marcado pela mais recente ruptura democrático-institucional ocorrida no Brasil - o golpe maquiado de impeachment contra a presidenta eleita Dilma Rousseff -, indicou uma nova inflexão ultraneoliberal, com uma investida intensiva na redução de direitos e no desmonte de políticas públicas, que incidiu diretamente na gestão urbana (Ribeiro e Bógus, 2018).

Acompanhando o golpe, uma onda de deslegitimação das mais diversas formas de ativismo instaurou-se, influenciando o recrudescimento da postura do poder público no tratamento das ocupações. 0 relativo sucesso conquistado por esses territórios passou a ser ameaçado, e muitas das ocupações que tentaram se consolidar nesse período foram despejadas, não raro com o uso de um aparato militar intensivo (como helicópteros e blindados). As primeiras ocupações a caírem foram Maria Guerreira e Maria Vitória, no bairro Copacabana. A ironia desse despejo, que marca o caráter truculento e contraditório da inflexão ultraneoliberal, é que as famílias foram removidas do terreno público da prefeitura que ocupavam na mesma semana em que ocorria um leilão de terrenos públicos alienados à empresa PBH Ativos.

Outra tentativa de ocupação que acabou em violência por parte da tropa de choque da 
polícia militar foi a Manuel Aleixo, organizada pelo MLB. No mesmo dia, a polícia, sem qualquer ordem judicial, retirou as famílias e os militantes com tiros de borracha e bombas de gás. ${ }^{37}$ Meses depois, a ocupação Lampião, organizada pelas brigadas populares, tentou se consolidar num terreno na Pampulha e também foi rapidamente ameaçada pela PM. Diante desse cenário, a avaliação dos movimentos era de promover um recuo tático. Não havia, ao menos até a metade do ano de 2017, condições de realização de novas ocupações de terreno.

No entanto, enquanto se consolidava esse cenário devastador de elevação do conservadorismo, do antiesquerdismo e da violência, gestava-se, no âmbito da organização popular, uma transformação das formas de atuação política e do repertório de ação dos movimentos. As eleições municipais entraram em pauta, mobilizando as redes criadas desde 2013 para estratégias de luta institucional. Ao mesmo tempo, pequenas ocupações de imóveis começaram a ganhar força no centro, levando a pauta do direito à cidade agora em confronto direto com o território do poder.

Um exemplo é a ocupação Kaza Invisível, criada de forma silenciosa por um coletivo anarquista em 2013, em uma casa abandonada na avenida Bias Fortes. Em 2016 o coletivo decidiu "abrir as portas da nova casa", sentindo que já havia segurança contra um possível despejo ilegal devido ao seu tempo de permanência. No dia 8 de março de 2016, o Movimento de Mulheres Olga Benário e o MLB ocuparam o prédio da antiga Escola de Engenharia da UFMG, na região central de Belo Horizonte, vazio havia dez anos, e criaram primeira ocupação de mulheres na América Latina - o Centro de Referência da Mulher Tina Martins ${ }^{38}$ - para abrigar e acolher mulheres vítimas de violência. Cabe ainda lembrar a resistência da Ocupação Zezeu Ribeiro e Norma Lucia, na rua Caetés, criada em 2015 pela Central de Movimentos Populares (CMP), o MNLM, a Conam e a UNMP. A ocupação fazia parte de uma ação de ocupações conjuntas no Brasil, durante o Fórum Nacional pela Reforma Urbana, e foi uma das poucas a continuar depois do evento.

Nos espaços públicos, ocupações urbanas e redes sociais, foi se construindo o entendimento de que os movimentos populares construídos e fortalecidos nos últimos anos deveriam influir nos rumos das eleições municipais de 2016 e fazer frente aos ditames neoliberais. A confluência de ativistas de diversas causas (lutas por moradia, mobilidade, questão indígena, feministas, movimento negro, LGBT, etc.) pela ocupação das eleições consolidou-se nas Muitas pela Cidade que Queremos, que construiu, com o Partido Socialismo e Liberdade (PSOL), uma plataforma eleitoral que se converteu no lançamento de candidaturas populares (Fonseca e Gonçalves, 2018).

Durante o ano de 2016, as Muitas realizaram diversas reuniões, eventos e debates para discutir uma nova forma de política - e de política urbana. Tudo parecia confluir para o centro: as propostas mais votadas nas redes sociais diziam respeito à moradia central e a ocupações de imóveis vazios e ociosos. Seguindo essa tendência, na busca por outras alternativas para a realização de ocupações, as Brigadas Populares começaram um mapeamento dos imóveis vazios da região central, através dos Rolezinhos da Função Social. ${ }^{39}$ Durante os eventos, mesclavam-se a procura de edificações e a entrega de panfletos nas ruas para promover a candidatura da militante das 
Brigadas Populares, Bella Gonçalves, ao cargo de vereadora pelas Muitas.

Das 12 candidaturas lançadas pelas Muitas, duas se elegeram, sendo Áurea Carolina a candidata mulher mais bem-votadas da história de Belo Horizonte (ibid.). Isabella Gonçalves não foi eleita por uma margem pequena de votos, mas criou uma iniciativa de covereança com a segunda vereadora eleita pela plataforma, Cida Falabella - liderança da área da cultura. Vários representantes de movimentos foram contratados como assessores do gabinete que se formou - batizado de Gabinetona - como forma de aproximar o espaço institucional do chão das lutas. ${ }^{40}$

Para além do legislativo, os movimentos ligados às ocupações também influenciaram a eleição do Executivo. Alexandre Kalil (PSH) conquistou o cargo de prefeito depois de realizar uma série de visitas às ocupações da Izidora e de se comprometer a encerrar as tentativas de despejo - o que foi amplamente utilizado em sua campanha. ${ }^{41}$ Em meio a essa conjuntura favorável de fissuras na política municipal, surgiu uma das ocupações organizadas mais emblemáticas de Belo Horizonte: Carolina Maria de Jesus. Organizada em setembro de 2017 pelo MLB em uma edificação abandonada no bairro Funcionários, a ocupação se tornou um símbolo de luta e resistência, abrigando 200 famílias em pleno segundo metro quadrado mais caro de Belo Horizonte. ${ }^{42}$ Devido ao nível de ousadia inédito alcançado pelo movimento, a ocupação sofreu os mais diversos ataques, e ainda assim conseguiu resistir bravamente por quase um ano.

Logo em seguida, no dia 7 de setembro em 2017, nasceu a Pátria Livre, organizada pelo Movimento de Trabalhadores por Direitos
(MTD) em um edifício abandonado na Pedreira Prado Lopes. Desde que foi criada, a ocupação tem sediado diversos eventos importantes como $01^{\circ}$ Fórum Mineiro BR Cidades, ${ }^{43}$ que discutiu, entre os temas da moradia, trabalho e gênero, o avanço da política neoliberal na gestão das cidades.

No ano seguinte, as Brigadas Populares, a Intersindical e a Associação Morada de Minas ocuparam um edifício abandonado no Centro, apenas a um quarteirão da atual Secretaria de Finanças, onde nasceu a Vicentão. A ação foi alimentada pela insatisfação quanto às ações de expulsão de trabalhadores ambulantes das ruas e de espaços públicos da região central e quanto à tentativa de inseri-los em edificações privadas, conhecidos como shoppings populares, através de Operações Urbanas Simplificadas. ${ }^{44}$ De forma inédita, a Vicentão abrigou ambulantes e famílias sem teto e confluiu as mobilizações pela dignidade do trabalho ambulante com a pauta da moradia no centro. Durante seu tempo de permanência, sediou também uma unidade do Cursinho Milton Santos e abrigou eventos como a Caravana do Direito à Cidade. ${ }^{45}$

Tanto Carolina Maria de Jesus quanto Vicentão - as ocupações de edificações centrais mais emblemáticas - conseguiram alcançar um espaço de diálogo com o poder público, permanecendo por muito mais tempo que as ocupações verticais anteriores a esse ciclo de dez anos. No entanto, com as eleições de 2018, as tensões acirraram-se: por um lado, ascenderam o conservadorismo e a perseguição aos ativismos, com a eleição de Jair Bolsonaro (PSL) a presidente e de Romeu Zema (Novo) a governador; por outro, fortaleceram-se as tentativas de tomada das instâncias políticas pelos 
movimentos organizados, agora na esfera estadual e federal. Nesse sentido, o Ocupa Política mostrou-se como a grande plataforma, confluindo a iniciativa as Muitas (MG), com a Bancada Ativista (SP), Chama (RJ) e Agora é com a Gente (PE), e lançando candidaturas a cargos legislativos em todo o Brasil. Áurea Carolina foi eleita deputada federal, abrindo espaço para Bella Gonçalves ocupar a Câmara como vereadora. Andréia de Jesus, militante das Brigadas Populares, foi eleita deputada estadual e se tornou a primeira mulher negra a ocupar um cargo no legislativo mineiro.

A avaliação dos movimentos sobre 0 cenário era do recrudescimento do aparato policial e da desqualificação da ocupação enquanto forma de ação política, o que gerou um sentimento de insegurança. 0 medo dos despejos violentos acabou influenciando na negociação das ocupações, fazendo com que os moradores aceitassem acordos menos vantajosos por medo de não conquistarem acordo algum. Buscando amenizar a situação, cabe destacar a realização do Encontro da Defensoria Pública e os movimentos sociais de luta pela moradia, no dia 5 de dezembro de 2018, que convidou a equipe de transição do governo Zema para dialogar, embora não tenha tido sucesso. Com a mesma preocupação, no dia 17 de dezembro, o Centro de Apoio Operacional das Promotorias de Justiça de Defesa dos Direitos Humanos (CAODH) realizou o II Colóquio entre Ministério Público, o Programa Diálogos Comunitários, ${ }^{46}$ os movimentos sociais e moradores das ocupações urbanas da capital.

Outra tentativa de barrar retrocessos foi a aprovação às pressas da atualização da Política Municipal de Habitação no Conselho Municipal de Habitação, no dia 13 de dezembro de
2018. Fruto de um processo iniciado em 2017, a revisão foi liderada pelo Coletivo Habite a Política, grupo de técnicos ativistas sindicalizados e acadêmicos que atuavam em rede com movimentos de luta por moradia (Paolinelli, 2018). 0 resultado incorporou as ocupações organizadas como assentamentos de interesse social e passou a prever ações de regularização e urbanização desses territórios na política municipal. Além disso, incluiu programas de locação social (de propriedade pública, privada e de associações) na provisão habitacional, dando prioridade à habitação central e à utilização de imóveis vazios e subutilizados.

No entanto, como os movimentos não estavam completamente inteirados sobre as transformações da política, já que se mobilizavam mais fora que dentro das esferas participativas tradicionais, o desfecho das ocupações verticais acabou pecando pela falta de um projeto viável de permanência. Tanto a negociação da Carolina quanto a da Vicentão resultaram no despejo, ainda que recursos públicos tenham sido garantidos na operação. A ocupação Carolina foi transferida para outro prédio, em uma negociação temporária e insegura com um novo proprietário, utilizando o apoio do governo por meio do auxílio pecuniário - uma espécie de bolsa moradia. ${ }^{47} \mathrm{~A}$ ocupação também iniciou uma negociação pela construção de habitações para as famílias em um terreno no Barreiro, que, pela conjuntura, pode ser prejudicada. Já a ocupação Vicentão não conseguiu encontrar uma edificação para se transferir e acabou tendo suas famílias dispersas pela cidade, através também do auxílio pecuniário. $A$ ideologia da casa própria, que influenciou diretamente as ocupações de terrenos - como criticado em Lourenço (2014) -, voltou-se contra as 
ocupações verticais e impediu que alternativas como a locação social, mais compatíveis com a moradia central, fossem consideradas. Sem um projeto de permanência vinculado a uma política pública, as ocupações sucumbiram às alternativas temporárias. 0 despejo da Vicentão, em fevereiro de 2019, marca, então, o fim desse importante ciclo de dez anos, deixando em aberto quais serão os próximos desdobramentos desse período de lutas.

\section{Considerações finais}

Durante os 10 anos de trajetória tratados neste artigo, os movimentos sociais de Belo Horizonte passaram por um amadurecimento que indicou um duplo movimento: por um lado a radicalização das ações e, por outro, a hibridação de várias pautas ligadas à vida na cidade. Essa estratégia tem, a nosso ver, uma razão de ser: a radicalidade e a articulação dos vários ativismos são uma poderosa ferramenta para a resistência contra o urbanismo neoliberal. De movimentos que se submetiam à política criada pela gestão municipal, insuficiente na provisão de habitação, as organizações populares deslocaram-se para a ação direta, com um destaque na formação e consolidação de ocupações organizadas - enquanto estratégia de luta, de produção de moradias e de criação de narrativas políticas de resistência.

Se, durante um primeiro estágio, esses movimentos de ação direta limitavam sua relação com o poder público somente na esfera da negociação e da defesa da posse, hoje se tem uma relação mais plural com as várias esferas do Estado e de instituições. A participação e incidência política dos movimentos, seja nas conferências municipais, no Legislativo ou na mobilização do Judiciário, acabaram por ampliar seu repertório de ação. Essa mudança deve obrigar a teoria sobre os movimentos sociais e ativismos a acompanhar sua crescente complexidade: não cabe mais quadros de análise maniqueístas que sustentam a prioridade da ora ação institucional, ora na ação direta autônoma. Parece que pelo menos alguns dos movimentos sociais de ocupações organizadas, como Brigadas Populares e o MLB, estão dispostos a matizar mais esse quadro, ampliando o leque de suas ações para o fortalecimento de suas pautas. Mas uma coisa é clara: a luta institucional torna-se um desdobramento, e não o objetivo. Como afirma Lopes de Souza (2012, p. 6):

[...] a luta institucional não substitui, em hipótese alguma, a ação direta; no fundo, subordina-se a ela, assim como a tática se subordina à estratégia, e não 0 contrário. Na fórmula "com o Estado, apesar do Estado, contra o Estado", empregada pelo autor deste texto em diversos trabalhos anteriores, são os dois últimos ingredientes - e principalmente o último deles - que devem predominar, de um ponto de vista que leve a sério o risco da cooptação e degeneração dos movimentos e que assuma a necessidade de uma mudança socioespacial profunda como pré-requisito para se poder falar, com rigor e consistência, em maior justiça social e melhorias substanciais da qualidade de vida da maior parte da população.

Assim, podemos sugerir que os movimentos do atual estágio da luta pela moradia em Belo Horizonte assentam-se em um tripé: 1) ação direta; 2) ação institucional; 3) ação 
cotidiana. Todas as três formas de ação são importantes espaços de formação que podem condicionar uma subjetividade insurgente naqueles que se envolvem e se deixam afetar nas lutas. Argumentou-se aqui que a ação cotidiana foi, durante esse período investigado, a substância fundamental para o fortalecimento das demais.

Entretanto, a verdadeira prova de fogo, que colocará o amadurecimento dos movimentos à prova, ainda parece estar por vir. 0 cenário que se delineou a partir de 2019, com a eleição de Jair Bolsonaro e de Romeu Zema, abrirá uma nova era para o ativismo. Em ambas as campanhas, os movimentos sociais de esquerda estavam na alça de mira - em especial aqueles que atuam com ocupações com o argumento do cumprimento da função social da propriedade, como o MST ou o MTST em âmbito nacional, e os movimentos aqui descritos no âmbito local. Bolsonaro prometeu acabar com os ativismos, e Zema prometeu reintegrar todas as propriedades imobiliárias para seus "donos". Se estas serão somente "promessas de campanhas" apenas o tempo irá dizer, mas fato é que um novo regime de urgência já está se delineando. Dessa maneira, apesar de todos os riscos que a ação institucional possa ter de "cooptação e degeneração dos movimentos" (Souza, 2014), essa frente de ação poderá desempenhar um papel importante por poder oferecer alguma segurança aos movimentos. Vai depender, no entanto, da capacidade das brechas que já foram conquistadas de resistir e perpetuar a radicalidade das pautas. Nesse sentido, o desafio maior não se dá apenas em evitar a cooptação nessa esfera, mas na manutenção das possibilidades de ação direta, e principalmente, de resistência no âmbito do cotidiano.

\section{[I] https://orcid.org/0000-0003-1458-1611}

Universidade Federal de Minas Gerais, Escola de Arquitetura, Urbanismo e Design, Programa de Pós-Graduação em Arquitetura e Urbanismo. Belo Horizonte, MG/Brasil.

marinasanderspaolinelli@gmail.com

\section{[II] https://orcid.org/0000-0003-3662-6104}

Universidade Federal de Minas Gerais, Instituto de Geociências, Programa de Pós-Graduação em Geografia. Belo Horizonte, MG/Brasil.

thiago.canettieri@gmail.com 


\section{Notas}

(1) Cidadania insurgente é um padrão de mobilização política das periferias urbanas discutido por Holston (2013), em que direitos básicos de cidadania são reivindicados por uma população trabalhadora marginalizada a partir de lutas em torno do espaço construído.

(2) Territórios em resistência, como argumentado por Zibechi (2015), são territórios urbanos baseados na relação entre terra e organização política cujas práticas trazem a ideia da autonomia, autodeterminação e autogoverno - conceitos originários na luta campesina e indígena.

(3) O primeiro movimento de luta pela moradia de dimensão nacional criado foi a União Nacional por Moradia Popular - UNMP (1989), resultado da organização que levou à construção do primeiro projeto de lei de iniciativa popular pela criação do fundo nacional de habitação. Em seguida, foram criados o Movimento Nacional de Luta por Moradia - MNLM (1990), a Central dos Movimentos Populares - CMP (1993), e o Movimento dos Trabalhadores Sem Teto - MTST (1997), entre outros.

(4) O Profavela foi o precursor das Zonas Especiais de Interesse Social (Zeis) (Bedê, 2005).

(5) Para uma definição do neoliberalismo enquanto normatividade prática e racionalidade governamental, ver Dardot e Laval (2016).

(6) Sobre o planejamento estratégico, deve-se ter em conta o que diz Vainer (2000, p. 78): "Procura-se evidenciar que este projeto de cidade implica a direta e imediata apropriação da cidade por interesses empresariais globalizados e depende, em grande medida, do banimento da política e da eliminação do conflito e das condições de 'exercício da cidadania'".

(7) Conceito desenvolvido por Harvey $(1996$, p. 53) para designar que "[...] a administração urbana se transformou em uma forma de capitalismo tardio". A produção da cidade se faz a partir de uma parceria público-privada, em que "[...] as tradicionais reivindicações locais são integradas com a utilização do poder público para atrair fontes externas de financiamento ou de investimento".

(8) Manifesto Programa Vila-Viva ou Vila-Morta?, de 2007, assinado por mais de vinte organizações (movimentos de luta por moradia, associações de bairro, rádios comunitárias e ocupações).

(9) Um retrato dessa situação, no caso do Aglomerado da Serra, é mostrado no documentário "Uma avenida em meu quintal", produzido pelo Programa de Extensão Polos de Cidadania da UFMG.

(10) O movimento originou-se em 2003, em Belo Horizonte, a partir do Núcleo de Estudos Marxistas (NEM); reorganizou-se anos depois com o nome de Brigadas Populares; e fundiu-se com organizações de outros estados, nacionalizando-se em 2011.

(11) Para uma análise detalhada dessa história e das experiências, conferir Bittencourt (2016).

(12) Sobre o funcionamento da PBH Ativos, conferir o trabalho de Canettieri (2017).

(13) Aqui, a gestão empresarial é usada para definir a prática de governo neoliberal da coisa pública que se realiza com base na lógica do empresariamento e que submete as políticas públicas à racionalidade própria do capital, ou seja, à lucratividade. Com isso, a ordem da política urbana pertence, ironicamente, ao âmbito da infrapolítica (Canettieri, 2017, p. 519). 
(14) Os participantes do evento são convidados a vestir trajes de praia e a se banhar nas fontes da praça. Depois do início do evento, as fontes foram desligadas, e os manifestantes passaram a arrecadar dinheiro informalmente para o aluguel de caminhões pipa, que viraram uma nova atração. O evento transformou-se também, posteriormente, em um bloco de carnaval e teve uma participação ativa no ressurgimento dos blocos de rua que reativaram o carnaval belohorizontino.

(15) Entre as queixas do movimento, estavam as medidas higienistas da guarda municipal, acusada pelo grupo de confiscar posses de moradores de rua; de ações truculentas contra ocupações; do projeto de demolição do Mercado Distrital do Cruzeiro, entre outros.

(16) Sobre a história da Dandara e seu processo de conformação, conferir o trabalho de Lourenço (2014), Bittencourt (2016) e Machado (2017).

(17) O PMCMV contou com mais de 200 mil inscritos, no ano de 2009 no município, e produziu, na faixa de renda de 0 a 3 salários mínimos (FAR), cerca de três mil unidades até o ano de 2012.

(18) Para uma história e análise dessas ocupações, ver Bittencourt (2016) e Bittencourt, Morado Nascimento e Goulart (2016).

(19) É preciso lembrar que várias ocupações espontâneas acabaram não tendo o mesmo desfecho.

(20) As APHs eram grandes reuniões de organização suprapartidária, geralmente realizadas embaixo do Viaduto Santa Tereza, onde mobilizações e manifestações eram planejadas.

(21) Comitês dessa natureza foram criados em diversas cidades que hospedaram a Copa no Brasil e atuavam em rede. As ações do comitê mineiro estenderam-se no período entre 2011 e 2014.

(22) A Izidora, como ficaram conhecidas as ocupações da região do Isidoro (Rosa Leão, Esperança e Vitória), é o maior assentamento informal da América Latina, com cerca de 8.000 famílias.

(23) Movimento aberto e horizontal pelo transporte público, gratuito e de qualidade.

(24) Ocupação artístico-cultural do casarão onde funcionou o Hospital de Neuropsiquiatria Infantil. O imóvel, de interesse do patrimônio histórico, estava abandonado havia quase vinte anos.

(25) Os ocupantes dos saguões dos prédios foram mantidos isolados, sem acesso à alimentação trazida por voluntários. A polícia também usou de força contra apoiadores que estavam do lado de fora; uma militante teve o braço fraturado por um policial e vários foram detidos.

(26) A operação, anunciada em outubro de 2013, envolvia cerca de $7 \%$ do município e havia sido desenvolvida por técnicos da prefeitura e de empresas de consultorias, sem participação popular. Os movimentos sociais, indignados, fizeram pressão nas reuniões do Conselho Municipal de Política Urbana, o que fez com que o Ministério Público iniciasse uma investigação sobre o projeto e enviasse uma recomendação para não ser votado (Indisciplinar, 2019a). Por fim, o projeto da Nova BH caiu e foi substituído por um processo participativo que resultou na Operação OUC ACLO.

(27) Campanha que unificou movimentos e ativistas ambientalistas contra o corte de centenas de Ficus nas avenidas Barbacena e Bernardo Monteiro, anunciado num projeto de recomposição paisagística da região. As árvores foram cortadas sob a alegação de uma infestação. $O$ movimento propôs seu tratamento e manutenção (Indisciplinar, 2019b).

(28) Movimento criado em 2014 que uniu a associação de moradores do bairro Jardim América, a universidade e ambientalistas pela preservação da mata nativa da chácara Jardim América, alvo de um projeto de empreendimento imobiliário de grande porte (Indisciplinar, 2019b). 
(29) Formado por mais de 40 professores, pesquisadores e alunos, o grupo sediado na Escola de Arquitetura da UFMG toca, desde 2013, atividades em atuação conjunta com movimentos sociais.

(30) Com a expectativa de derrubar o quórum de participação do setor empresarial e, assim, impedir a continuidade do processo, um grupo liderado pela Câmara do Mercado Imobiliário de Minas Gerais (CMI/Secovi-MG) e o Sindicato da Indústria da Construção Civil no Estado de Minas Gerais (Sinduscon-MG) se retirou da conferência em massa. No entanto, o regimento do evento dava respaldo para sua continuação, que seguiu normalmente durante muitos meses.

(31) A votação em primeiro turno do Projeto de Lei 1749/15 referente à atualização do Plano Diretor ocorreu apenas no dia 22 de novembro de 2018, faltando ainda, nesse momento, todo o trâmite regimental de apresentação de emendas, apreciação nas comissões e a votação em segundo turno, ainda sem previsão. A história desse processo de tramitação merece uma análise mais detalhada, que vem sendo trabalhada pelos autores em parceria com outros pesquisadores.

(32) Encabeçada pelas mesmas lideranças que deixaram a conferência, a campanha produziu uma série de outdoors e materiais nas redes sociais acusando o município de criar um "novo imposto sobre moradias", referindo-se à aplicação da OODC nos empreendimentos imobiliários em zonas valorizadas previstas no plano.

(33) Além de desmentir uma série de alegações do setor empresarial, essa campanha tem mobilizado uma ampla rede de organizações (movimentos de ocupação, transporte, quilombolas, estudantes e até técnicos da prefeitura) através da produção de materiais em redes sociais e da criação de eventos para pressionar o Executivo e o Legislativo pela aprovação do plano.

(34) As violações de direitos contra as ocupações da Izidora foram julgadas no Tribunal Internacional de Despejos em Quito (Equador). O caso foi selecionado como um dos 7 mais graves do mundo.

(35) O curta-metragem Na missão, com Kadu (Aiano Bemfinca e Pedro Maia de Brito, 2016) mostra os momentos de terror vividos quando bombas atingiram a manifestação pacífica, que era composta também por crianças e idosos. O curta foi finalista no Grande Prêmio pela Academia Brasileira de Cinema e colecionou várias premiações locais, nacionais e internacionais.

(36) Tonucci Filho (2017) relaciona a vida cotidiana nas ocupações com a prática política a partir da ideia de comum urbano. Em Bastos et al. (2017), a produção do cotidiano nas ocupações é discutida enquanto criação de um espaço diferencial, nos termos lefebvrianos.

(37) Um dos tiros atingiu o rosto de Gabi, uma menina de apenas 11 anos, perfurando sua face e destruindo parte de seu maxilar. O movimento MLB denunciou o ato criminoso da polícia e também se organizou para arrecadar recursos para a cirurgia a que a jovem teve que se submeter.

(38) Depois de uma longa negociação, a ocupação foi transferida para a rua Paraíba, no bairro Funcionários, em uma casa de cessão temporária garantida pelo governo do Estado.

(39) Nas duas edições do evento, um grupo de militantes e apoiadores percorria a região central de Belo Horizonte levantando imóveis vazios com potencial de transformação em habitação. 
(40) Diversos instrumentos têm sido utilizados pelo mandato para experimentar canais de participação direta: laboratórios populares de lei (Labpop) - encontros temáticos convocados para discutir a incidência do gabinete em projetos de lei, produzindo emendas e pareceres; os grupos fortalecedores (Gêfortes) - grupos de referência para refletir sobre a atuação parlamentar em assuntos e questões urgentes; Zonas megafônicas - encontros políticos para buscar conectar, amplificar e aumentar a visibilidade das lutas sociais em Belo Horizonte; Zonas de Confluência - espaços transversais construídos para conectar setores da luta popular, a fim de fortalecê-los.

(41) Uma das peças publicitárias da campanha de Kalil dizia "Izidora também é Belo Horizonte e tem que funcionar", com uma imagem do candidato junto a lideranças da ocupação.

(42) Segundo a Pesquisa Casa Mineira sobre o valor de imóveis em Belo Horizonte de 2016.

(43) O Fórum fez parte de uma articulação brasileira e contou com a presença de Ermínia Maricato, integrante do comitê nacional.

(44) Instrumento municipal que permite, a empreendedores privados, flexibilizações na legislação urbanística, principalmente em termos de potencial construtivo, em troca de contrapartidas.

(45) Atividade da Gabinetona de fortalecimento do diálogo com os territórios populares. A edição do evento, realizado no terraço comunitário da edificação em junho de 2018 , contou com a presença de movimento de ocupação, lideranças indígenas, ambulantes e artistas residentes na ocupação.

(46) Programa de parceria entre o Ministério Público do Estado de Minas Gerais (MPMG) e a Cáritas Brasileira Regional Minas Gerais (Cáritas-MG), firmado em 2016 e formalizado em 2017.

(47) O Bolsa Moradia é um programa municipal que oferece auxílio mensal para famílias alugarem moradias no mercado privado, que são vistoriadas pela Urbel. Já o Auxílio Pecuniário, instituído recentemente pela lei n. 11.148/2019, é um auxílio flexibilizado, que pode ser utilizado para garantir a moradia das mais diversas formas, e não possui controle do município.

\section{Referências}

ARANTES, P. F. e FIX, M. (2009). Como o governo Lula pretende resolver o problema da habitação. Caros Amigos, pp. 1-25.

BASTOS, C. D.; MAGALHÃES, F.; MIRANDA, G. M.; SILVA, H.; TONUCCI FILHO, J. B. M.; CRUZ, M. M. e VELLOSO, R. C. L. (2017). Entre o espaço abstrato e o espaço diferencial ocupações urbanas em Belo Horizonte. Revista Brasileira de Estudos Urbanos e Regionais, v. 19, pp. 251-266.

BEDÊ, M. (2005). Trajetória da formulação e implantação da política habitacional de Belo Horizonte na gestão da Frente BH Popular 1993-1996. Dissertação de Mestrado. Belo Horizonte, Universidade Federal de Minas Gerais.

BITTENCOURT, R. (2016). Cidadania autoconstruída: o ciclo de lutas sociais das ocupações urbanas na $R M B H$ (2006-15). Dissertação de Mestrado. Belo Horizonte, Universidade Federal de Minas Gerais. 
BITTENCOURT, R.; MORADO NASCIMENTO, D. e GOULART, F. (2016). Ocupações urbanas na Região Metropolitana de Belo Horizonte. Belo Horizonte, Favela é isso aí.

BIZOTTO, L. (2015). \#RESISTEIZIDORA: controvérsias do movimento de resistência das Ocupações da Izidora e apontamentos para a justiça urbana. Dissertação de Mestrado. Belo Horizonte, Universidade Federal de Minas Gerais.

CANETTIERI, T. (2014). Ocupações, remoções e luta no espaço urbano: a questão da moradia. E-metropolis: Revista eletrônica de Estudos Urbanos e Regionais, v. 5, pp. 22-29.

(2017). A produção capitalista do espaço e a gestão empresarial da política urbana: o caso da PBH Ativos S/A. Revista Brasileira de Estudos Urbanos e Regionais, v. 19, n. 3, pp. 513-528.

DARDOT, P. e LAVAL, C. (2016). A nova razão do mundo: ensaio sobre a sociedade neoliberal. São Paulo, Boitempo.

FONSECA, H. e GONÇALVES, R. (2018). Possibilidades contra-hegemônicas: reinventar a política é possível? V!RUS. São Carlos, n. 17.

FRANCO, S. (2007). Democracia, socialismo e o urbano: reflexões a partir da experiência dos governos de Frente de Esquerda na cidade de Belo Horizonte. Dissertação de Mestrado. Belo Horizonte, Universidade Federal de Minas Gerais.

FRANZONI, J. (2018). O direito e o direito: estórias da Izidora contadas por fabulações jurídico-espaciais. Tese de Doutorado. Belo Horizonte, Universidade Federal de Minas Gerais.

FREITAS, L. F. (2015). Do Profavela à Izidora: a luta pelo direito à cidade em Belo Horizonte. Dissertação de Mestrado. Belo Horizonte, Universidade Federal de Minas Gerais.

GUERREIRO, I. (2017). A produção do espaço urbano pelo Lulismo: contradições específicas da dependência. In: XVII ENCONTRO NACIONAL DA ASSOCIAÇÃO NACIONAL DE PÓS-GRADUAÇÃO E PESQUISA EM PLANEJAMENTO URBANO E REGIONAL. Anais. São Paulo, Anpur.

HARVEY, D. (1996). Do gerenciamento ao empresariamento: a transformação da administração urbana no capitalismo tardio. Espaço \& Debates, ano 16, n. 39, pp. 48-63.

HOLSTON, J. (2013). Cidadania insurgente: disjunções da democracia e da modernidade no Brasil. São Paulo, Companhia das Letras.

INDISCIPLINAR (2019a). OUC Nova BH. Blog Indisciplinar. Disponível em: http://oucbh.indisciplinar. com/?page_id=17. Acesso em: 12 mar 2019.

(2019b). Natureza Urbana. Blog Indisciplinar. Disponível em: http://naturezaurbana.indisciplinar. com/. Acesso em: 12 mar 2019.

LOPES DE SOUZA, M. (2012). Ação direta e luta institucional: complementaridade ou antítese? Passe Palavra. Disponível em: http://passapalavra.info/2012/04/56901/. Acesso em: 12 mar 2019.

LOURENÇO, T. (2014). Cidade ocupada. Dissertação de Mestrado. Belo Horizonte, Universidade Federal de Minas Gerais.

MACHADO, B. R. (2017). Sobre o rururbano: a ocupação Dandara e os desafios da luta por moradia para além do rural e do urbano. Dissertação de Mestrado. Viçosa, Universidade Federal de Viçosa.

MARICATO, E. (2003). Metrópole, legislação e desigualdade. Estudos avançados, v. 17, n. 48, pp. $151-167$.

MELO, I. (2011). Vila Viva: desentendimentos. Piseagrama. Belo Horizonte, n. 4, pp. 14-16. 
NEVES, B.; MARQUES, L. H.; PIMENTA, M.; BRANDÃO, M. e RENA, N. (2018). "Breve cartografia das lutas territoriais em Belo Horizonte". In: ROLNIK, R.; SANTORO, P.; MORADO NASCIMENTO, D.; FREITAS, D.; RENA, N. e PEQUENO, L. Cidade Estado Capital: reestruturação urbana e resistência em Belo Horizonte, Fortaleza e São Paulo. São Paulo, FAUUSP.

OLIVEIRA, F. (2003). Crítica da razão dualista /O ornitorrinco. São Paulo, Boitempo.

PAOLINELLI, M. (2018). Desmercantilização da habitação: entre a luta e a política pública. Dissertação de Mestrado. Belo Horizonte, Universidade Federal de Minas Gerais.

RIBEIRO, L. C. e BÓGUS, L. (2018). As metrópoles no atual padrão de expansão do capitalismo. Cadernos Metrópole. São Paulo, v. 20, pp. 613-623.

TOFANELLI, V. (2018). Dos trabalhos coletivos aos coletivos de trabalho: uma experiência agroecológica em uma ocupação urbana. Dissertação de Mestrado. Belo Horizonte, Universidade Federal de Minas Gerais.

TONUCCI FILHO, J. B. (2017). Comum urbano: a cidade além do público e do privado. Tese de Doutorado. Belo Horizonte, Universidade Federal de Minas Gerais.

VAINER, C. (2000). "Pátria, empresa e mercadoria”. In: MARICATO, E.; ARANTES, O. e VAINER, C. (orgs.). Cidade do pensamento único: desmanchando consensos. Petrópolis/Rio de Janeiro, Vozes.

VALLE, W. (2015). Produção colaborativa de valores de uso em ocupações urbanas: concepção técnica e política do espaço. Dissertação de Mestrado. Belo Horizonte, Universidade Federal de Minas Gerais.

VELOSO, A. (2015). O ônibus, a cidade e a luta. Dissertação de Mestrado. Belo Horizonte, Universidade Federal de Minas Gerais.

ZIBECHI, R. (2015). Territórios em resistência. São Paulo, Consequência.

Texto recebido em 3/mar/2019 Texto aprovado em 12/abr/2019 
